Research Paper

\title{
Enhanced Expression of Sodium Hydrogen Exchanger (NHE)-1, 2 and 4 in the Cervix of Ovariectomised Rats by Phytoestrogen Genistein
}

\author{
Nurain Ismail ${ }^{1}$, Nelli Giribabuํㅜ, Sekaran Muniandy² and Naguib Salleh ${ }^{1 \bowtie}$ \\ 1. Dept of Physiology, Faculty of Medicine, University of Malaya, 50603 Lembah Pantai, Kuala Lumpur, Malaysia. \\ 2. Dept of Molecular Medicine, Faculty of Medicine, University of Malaya, 50603 Lembah Pantai, Kuala Lumpur, Malaysia. \\ $\triangle$ Corresponding author: E-mail: naguib.salleh@yahoo.com.my; Tel.: +6-017-208-271; Fax: +6-03-7967-4775
}

() 2015 Ivyspring International Publisher. Reproduction is permitted for personal, noncommercial use, provided that the article is in whole, unmodified, and properly cited. See http:/ /ivyspring.com/terms for terms and conditions.

Received: 2014.11.30; Accepted: 2015.04.07; Published: 2015.06.02

\begin{abstract}
Restoring the $\mathrm{pH}$ of cervicovaginal fluid is important for the cervicovaginal health after menopause. Genistein, which is a widely consumed dietary health supplement to overcome the post-menopausal complications could help to restore the cervicovaginal fluid $\mathrm{pH}$. We hypothesized that genistien effect involves changes in expression of NHE-1, 2 and 4 proteins and mRNAs in the cervix. This study investigated effect of genistein on NHE-1, 2 and 4 protein and mRNA expression in the cervix in order to elucidate the mechanisms underlying possible effect of this compound on cervicovaginal fluid $\mathrm{pH}$ after menopause. Methods: Ovariectomised adult female rats received 25,50 and $100 \mathrm{mg} / \mathrm{kg} /$ day genistein for seven consecutive days. At the end of the treatment, animals were sacrificed and cervix was harvested. Expression of Nhe-l, 2 and 4 mRNA were analyzed by Real-time PCR while distribution of NHE-1, 2 and 4 protein were observed by immunohistochemistry. Results: Treatment with 50 and $100 \mathrm{mg} / \mathrm{kg} /$ day genistein caused marked increase in the levels of expression and distribution of NHE-1, 2 and 4 proteins in the endocervical epithelia. Levels of Nhe-I, 2 and 4 mRNA in the cervix were also increased. Coadministration of $\mathrm{ICl} 182780$ and genistein reduced the expression levels of NHE-1, 2 and 4 proteins and mRNAs in the cervix. Conclusions: Enhanced expression of NHE-1, 2 and 4 proteins and mRNAs expression in cervix under genistein influence could help to restore the cervicovaginal fluid $\mathrm{pH}$ that might help to prevent cervicovaginal complications related to menopause.
\end{abstract}

Key words: genistein, NHE-1, 2 and 4, cervix

\section{Introduction}

Phytoestrogen genistein, which can be found in soy-based food products, is widely consumed as a health supplement by the post-menopausal women [1]. Genistein has been proven useful in reducing the risk of cardiovascular diseases after menopause [2], protects against post-menopausal osteoporosis [3], relieves post-menopausal symptoms such as hot flushes [4] and overcoming post-menopausal female reproductive complications such as altered cervical and vaginal fluid $\mathrm{pH}$, vaginal dryness and cervical atrophy [1]. Despite of these health benefits, over-consumption of genistein could predispose the uterus to neoplasia [5] and triggers deranged development of the female reproductive tract in fetus [6]. The effect of genistein is mainly attributed to its ability to bind to estrogen receptor [7], which made this compound an alternative treatment to alleviate post-menopausal complications related to estrogen deficiency.

Cervix, which connects vagina and the uterus, functions to restore the sperm prior to entry into the uterine lumen [8]. Cervix produces mucus which consistency changes throughout the female reproductive cycle. $\mathrm{pH}$ of the cervical secretion changes 
throughout the cycle, being high before ovulation due to increased in $\mathrm{HCO}_{3}^{-}$content [9]. The alkaline cervical fluid $\mathrm{pH}$ is necessary for sperm capacitation [10] and aids in the expansion of polyanionic macromolecular mucins, [9]. $\mathrm{pH}$ of the cervical fluid may influence the vaginal fluid $\mathrm{pH}$. Genistein, which shares similar characteristics to estrogen could help to restore the cervical fluid $\mathrm{pH}$ after menopause, thus this could influence the vaginal fluid $\mathrm{pH}$. As the results, the overall effect of genistein on cervicovaginal fluid $\mathrm{pH}$ could help to reduce the cervicovaginal complications related to estrogen deficiency.

Sodium-proton exchanger (NHE), which is involved in the $\mathrm{H}^{+}$flux across the absorptive and secretory epithelia has been reported to participate in $\mathrm{H}^{+}$secretion that aid in reabsorption of $\mathrm{HCO}_{3}{ }^{-}$in the kidney's ascending loop of Henle [11]. NHE-2 and NHE-3 was found to participate in $\mathrm{Na}^{+}$reabsorption in exchanged with $\mathrm{H}^{+}$secretion during acidification of the epididymal fluid. NHE has also been proposed to participate in uterine fluid $\mathrm{pH}$ regulation under the estrogen influence [12]. The mechanisms by which NHE might be involved in increasing the $\mathrm{pH}$ of uterine fluid are not fully understood, however this membrane transporter could help to ensure a continuous $\mathrm{HCO}_{3}{ }^{-}$secretion into the lumen by facilitating $\mathrm{HCO}_{3}$-regeneration in the epithelial cells. In view that genistein has been shown to cause increased in uterine fluid $\mathrm{pH}$ [13], therefore this compound might directly or indirectly affect the cervical NHE expression and activity. Currently, the effect of genistein on cervical fluid $\mathrm{pH}$ is unknown. We hypothesized that genistein could affect expression of NHE in the cervix that might contribute towards restoration of cervical fluid $\mathrm{pH}$ which could indirectly influence the vaginal fluid $\mathrm{pH}$. This study therefore investigated effect of genistein on NHE-1, 2 and 4 expression (similar isoforms expressed in the uterus) in the cervix of ovariectomised rats represents post-menopause model. Changes in expression of these isoforms under genistein influence could explain ability of this compound to restore the cervicovaginal fluid $\mathrm{pH}$ after menopause.

\section{Materials and methods}

\section{Animals and hormones treatment}

Adult female Sprague-Dawley (SD) rats weighing 200 - $225 \mathrm{~g}$ were obtained from Animal House, Faculty of Medicine, University of Malaya and were kept in a clean and well ventilated environment: temperature was kept $23 \pm 2 \mathrm{C}$ with $12 \mathrm{~h}$ light: $12 \mathrm{~h}$ dark cycle and $30-70 \%$ humidity. The animals had free access to soy-free diet (Harlan, Germany) and tap water ad libitum. All experimental procedures were approved by the Faculty of Medicine ethics committee with ethics number: 2013-07-15/FIS/R/NS. Genistein was purchased from LC laboratories (Woburn, MA, USA) with $99 \%$ purity. All other chemicals were of analytical grades. Ovariectomy was performed under isoflurane anesthesia two weeks prior to the treatment to remove the effect of endogenous sex-steroids. The rats were given intramuscular injection of $0.1 \mathrm{ml}$ kombitrim antibiotic to prevent post-surgical wound infection. Animals were divided into the following groups ( $\mathrm{n}=6$ per groups): (control)

Group 1: seven days treatment with peanut oil

Group 2, 3 \& 4: seven days treatment with 25, 50 and $100 \mathrm{mg} / \mathrm{kg} /$ day genistein respectively

Additional groups received estrogen receptor blocker (ICI 182 780) only or $100 \mathrm{mg} / \mathrm{kg} /$ day genistein with ICI 182780

A day after the last treatment, animals were sacrificed via cervical dislocation. Abdominal cavity was cut open and cervix was removed for tissue analyses.

\section{Quantification of Nhe-1, 2, and 4 isoforms mRNA by Real Time PCR}

Tissues were rinsed with $0.1 \%$ phosphate buffer and kept in RNALater solution (Ambion, Austin, TX, USA). Total RNAs were extracted by using RNeasy plus Mini Kit (Qiagen, Hilden, Germany) with their purity and concentration were assessed by determining the 260/280 UV absorption ratios (Gene Quant 1300, UK). The extracted RNAs were run on agarose gel to check for their integrity. RNAs were reversely transcribed into cDNA using a high capacity RNA-to-cDNA kit (Applied Biosystems, USA). One step Real Time PCR was performed to evaluate gene expression with the application of TaqMan ${ }^{\circledR}$ RNA-to-CT 2-Step Kit. The amplified region of cDNA was probed with a fluorescence-labeled probe. Gapdh was used as reference or house-keeping gene as its expression was the most stable in the endometrium throughout the oestrus cycle [14].

PCR program included $15 \mathrm{~min}, 48 \mathrm{C}$ reverse transcriptase, $10 \mathrm{~min}, 95 \mathrm{C}$ activation with ampliTaq gold DNA polymerase, denaturing at $95 \mathrm{C}, 15 \mathrm{~s}$ and annealing at $60 \mathrm{C}$ for $1 \mathrm{~min}$. Denaturing and annealing were performed for 40 cycles. Measurements were normalized with GenEx (MultiD, Sweden) followed by Data Assist v3 (Applied Biosystems, USA) software. The latter was used to calculate the RNA fold changes. All experiments were carried out in triplicates. TaqMan ${ }^{\circledR}$ primers and probes were obtained from pre-designed assays (Applied Biosystems, USA) with Nhe- 1, 2 and 4 assay numbers are Rn01418250, Rn006888610 and Rn01437220-m1 respectively while the assay number for Gapdh is Rn99999916-s. Data was 
analyzed according to Comparative $\mathrm{Ct}(2-\Delta \Delta \mathrm{Ct})$ method. Relative quantity of the target in each sample was determined by comparing the normalized target quantity of genes to normalized target quantity of reference.

\section{Immunoperoxidase and immunofluorescence detection of NHE-1, 2 and 4 isoforms protein}

Cervix were fixed in 10\% formalin overnight prior to processing and dehydrated through increasing concentrations of ethanol, cleared in chloroform and blocked in paraffin wax. Tissues were then sectioned into $5 \mu \mathrm{m}$ thicknesss, deparaffinized in xylene, rehydrated in reducing concentrations of ethanol. Tri-EDTA buffer (10mM Tris Base, $1 \mathrm{mM}$ EDTA solution, $0.05 \%$ Tween 20, $\mathrm{pH} 9.0$ ) was used for antigen retrieval. $1 \% \mathrm{H}_{2} \mathrm{O}_{2}$ in methanol was used to neutralize the endogenous peroxidase. Sections were blocked in donkey serum (sc-2044) to prevent non-specific antibody binding prior to incubation with goat polyclonal NHE-1 (sc-33325), NHE-2 (sc-16099) and NHE-4 (sc-16104) primary antibodies (Santa Cruz Biotechnology, CA, USA) at a dilution of 1:100 in blocking serum. Sections were then incubated at $4 \mathrm{C}$ overnight. $24 \mathrm{~h}$ later, the sections were rinsed three times in PBS, five min each and incubated with biotinylated secondary antibody for $1 \mathrm{~h}$ at room temperature. Localization of proteins was made by DAB (3,3'-Diaminobenzidine) (Santa Cruz, CA, USA) staining, which gave dark-brown stains at the site of the binding of primary antibody linked to secondary antibody conjugated with HRP complex (Immunocruz, ABC staining system, Santa Cruz, CA, USA). The sections were rinsed five min each with deionized water and counterstained with hematoxylin to visualize the nuclei. The slides were dehydrated with different dilution of ethanol and xylene and were covered with a drop of DPX neutral mounting medium (Labchem Inc, Georgetown, ON, USA).

For immunofluorescence staining, the sections were blocked in 10\% normal donkey serum (Sc-2044) (Santa Cruz Biotechnology, CA, USA) prior to incubation with NHE-1, 2 and 4 primary antibodies at dilution as above (Santa Cruz Biotechnology, CA) with $1.5 \%$ normal blocking serum at room temperature for one $\mathrm{h}$. After three times rinsing with PBS, the sections were incubated with IgG-fluorochromeconjugated donkey anti-goat secondary antibody (Sc-2024) (Santa Cruz Biotechnology, CA, USA) at a dilution of 1:250 in PBS with 1.5\% normal blocking serum at room temperature for $45 \mathrm{~min}$. The slides were rinsed three times with PBS and were mounted with Ultracruz mounting medium (Santa Cruz Biotechnology, CA, USA). The slides were counterstained to visualize the nuclei.

\section{Evaluation of immunoperoxidase and immunofluorescence staining intensity}

The slides were viewed under Nikon Eclipse 80i microscope (SEO Enterprises Inc, Lakeland, FL, USA) with attached Nikon DS Ri1 12 megapixel camera (Nikon, Tokyo, Japan). Immunoperoxidase and immunofluoresence images were captured under standardized condition of illumination. The photographs were taken at a fixed exposure time. The tiff images $(1280 \times 1024$ pixels $)$ were taken at objective lens magnification of 40×. By using NIS-Element AR program (Nikon Instruments Inc, Melville, NY, USA), the exposure time and sensitivity were set prior to image capturing. Slide with no tissue (blankfield) was viewed under the microscope and an auto white balance was performed. Areas of interest on the images were selected and total counts (spots with dark-brown stained/ fluorescence signals) were obtained. The mean intensity of dark brown stain/ signals (which could be restricted) was determined which represents the average amount of protein in the tissues. Average intensity was obtained from four different sections of four different rats receiving similar treatment.

\section{Statistical analyses}

Statistical differences were evaluated by one-way ANOVA. A probability level of less than 0.05 $(p<0.05)$ was considered as significant. Post-hoc statistical power analysis was performed for all experiments and values were $>0.8$ which indicate adequate sample size. Meanwhile, Shapiro-Wilk test was performed and all values obtained were $>0.05$ which indicate data normality. For mRNA quantification, mean value for each group was obtained from six (6) rats while for protein expression and histology, mean value for each group was obtained from four (4) rats.

\section{Results}

\section{Distribution of NHE-1 protein in endocervix}

Figures 1a and 2a show distribution of NHE-1 in endocervical epithelia of genistein-treated ovariectomised rats. NHE-1 protein was highly distributed at the apical membrane of epithelia lining the endocervical lumen in 50 and $100 \mathrm{mg} / \mathrm{kg} /$ day genistein treated rats as compared to control. Lower signals/ staining were observed in rats which received 25 $\mathrm{mg} / \mathrm{kg} /$ day genistein treatment as compared to 50 and $100 \mathrm{mg} / \mathrm{kg} /$ day genistein treatments.

\section{Distribution of NHE-2 protein in endocervix}

Figures $3 \mathrm{a}$ and $4 \mathrm{a}$ show distribution of NHE-2 protein in endocervical epithelia of genistein-treated ovariectomised rats. The highest NHE-2 protein distribution was observed in rats which received 50 and 
$100 \mathrm{mg} / \mathrm{kg} /$ day genistein treatments. Low distribution was observed in rats which received 25 $\mathrm{mg} / \mathrm{kg} /$ day genistein treatment.

\section{Distribution of NHE-4 protein in endocervix}

Figures $5 \mathrm{a}$ and $6 \mathrm{a}$ show distribution of NHE-4 protein in the luminal epithelia of endocervix in genistein-treated ovariectomised rats. The distribution was the highest at the apical membrane of endocervical epithelia of 50 and $100 \mathrm{mg} / \mathrm{kg} /$ day genistein-treated rats. Lower distribution was observed in rats which received $25 \mathrm{mg} / \mathrm{kg} /$ day genistein treatment as compared to 50 and $100 \mathrm{mg} / \mathrm{kg} /$ day genistein treatments.

\section{Levels of expression of NHE-1, 2 and 4 protein in the luminal epithelia of endocervix}

Quantitative analyses of fluorescence signals (figure $1 b, 3 b$ and $5 b$ ) and dark-brown staining (figure $2 \mathrm{~b}, 4 \mathrm{~b}$ and $6 \mathrm{~b}$ ) revealed that the highest levels of expression of NHE-1, 2 and 4 protein were observed in the luminal epithelia of the endocervix of 100 $\mathrm{mg} / \mathrm{kg} /$ day genistein treated rats, followed by $50 \mathrm{mg} / \mathrm{kg} /$ day genistein-treated rats. Low levels of expression was observed in rats receiving 25 $\mathrm{mg} / \mathrm{kg} /$ day genistein treatment.

a)
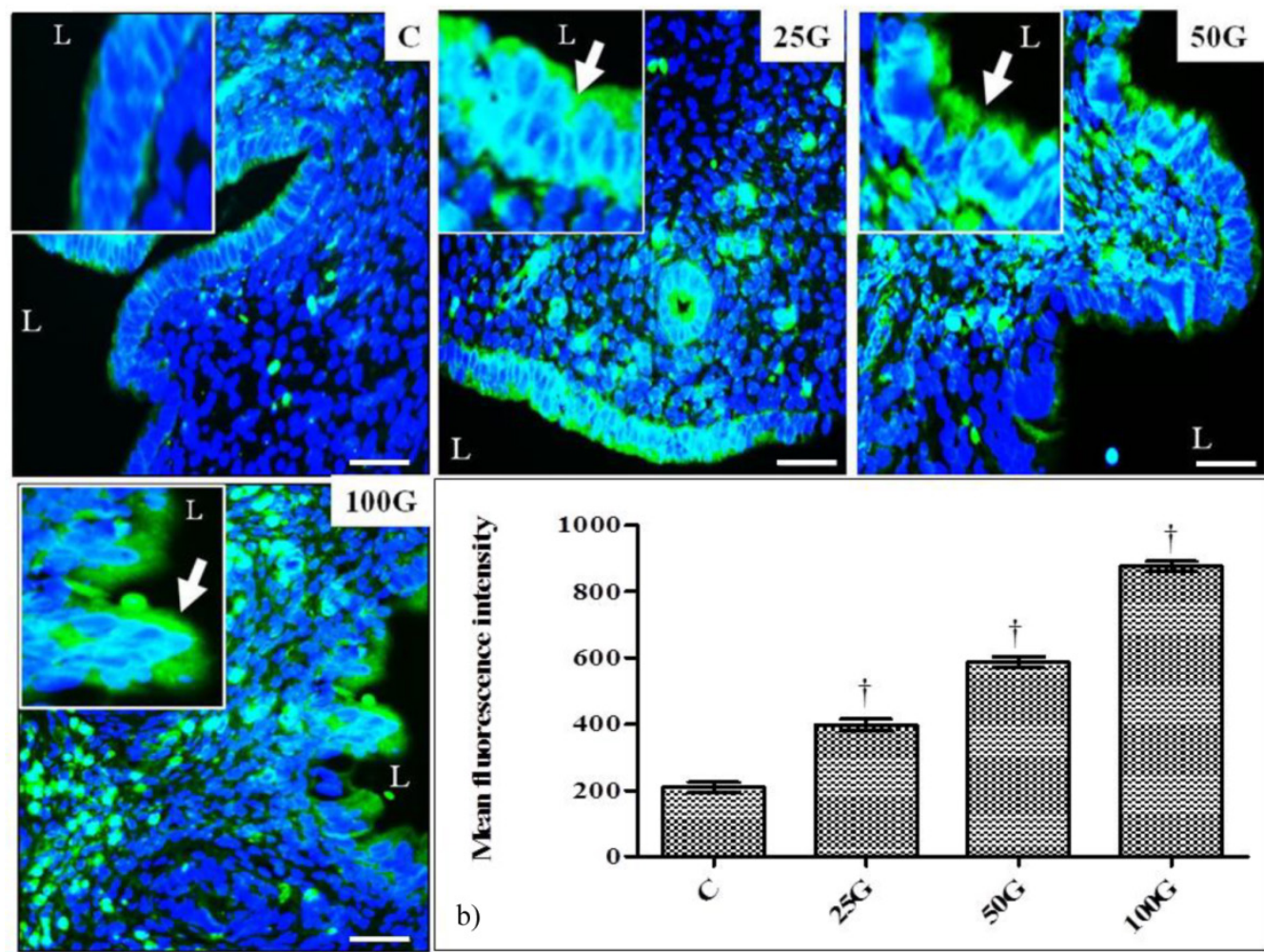

Figure 1: (a) Immunofluorescence images of NHE-1 in cervix. High intensity signals were seen at apical membrane of endocervical epithelia under $100 \mathrm{mg} / \mathrm{kg} / \mathrm{day}$ genistein. Lower signals were seen at apical membrane of endocervical epithelia following treatment with 50 and $25 \mathrm{mg} / \mathrm{kg} /$ day genistein (b) Quantitative analyses of fluorescence signals for NHE-1 in endocervical epithelia under genistein influence. The fluorescence signal intensity was highest in $100 \mathrm{mg} / \mathrm{kg} /$ day genistein treated group. Signal intensity in all groups of treatment was higher than control. C: control, 25G: $25 \mathrm{mg} / \mathrm{kg} /$ day genistein, $50 \mathrm{G}: 50 \mathrm{mg} / \mathrm{kg} /$ day genistein, $100 \mathrm{G}: 100 \mathrm{mg} / \mathrm{kg} /$ day genistein. Arrows pointing toward NHE-1. $†$ p<0.05 as compared to C. scale bar: $50 \mu \mathrm{m}$

\section{Expression levels of Nhe-1, 2 and 4 mRNA in}

Figure 7 shows the levels of expression of Nhe-1, ovariectomized rats receiving genistein treatment. The levels of expression of NHE-1, 2 and 4 mRNAs were the highest in cervix of rats which received 100 $\mathrm{mg} / \mathrm{kg} /$ day genistein treatment. Significantly lower mRNA expression levels were observed following 50 and $25 \mathrm{mg} / \mathrm{kg} /$ day genistein treatments $(\mathrm{p}<0.05$ as compared to $100 \mathrm{mg} / \mathrm{kg} /$ day genistein treatment). The levels of mRNA expression in $25 \mathrm{mg} / \mathrm{kg} /$ day genistein treated rats were higher than control.

\section{Effects of ICI 182780 on NHE-1, 2 and 4}

Figure 8a shows distribution of NHE-1, 2 and 4 proteins in endocervical epithelia while figure $8 \mathrm{~b}$ shows quantitative analysis of the intensity of fluorescence signals in rats receiving $100 \mathrm{mg} / \mathrm{kg} /$ day genistein with or without ICI 182780 treatment. Our findings indicated that the intensity of fluorescence signals was significantly reduced following concomitant $100 \mathrm{mg} / \mathrm{kg} /$ day genistein and ICI 182780 treatment as compared to $100 \mathrm{mg} / \mathrm{kg}$./ day genistein-only treatment. 2 and 4 mRNAs in cervical tissue homogenates of 
a)

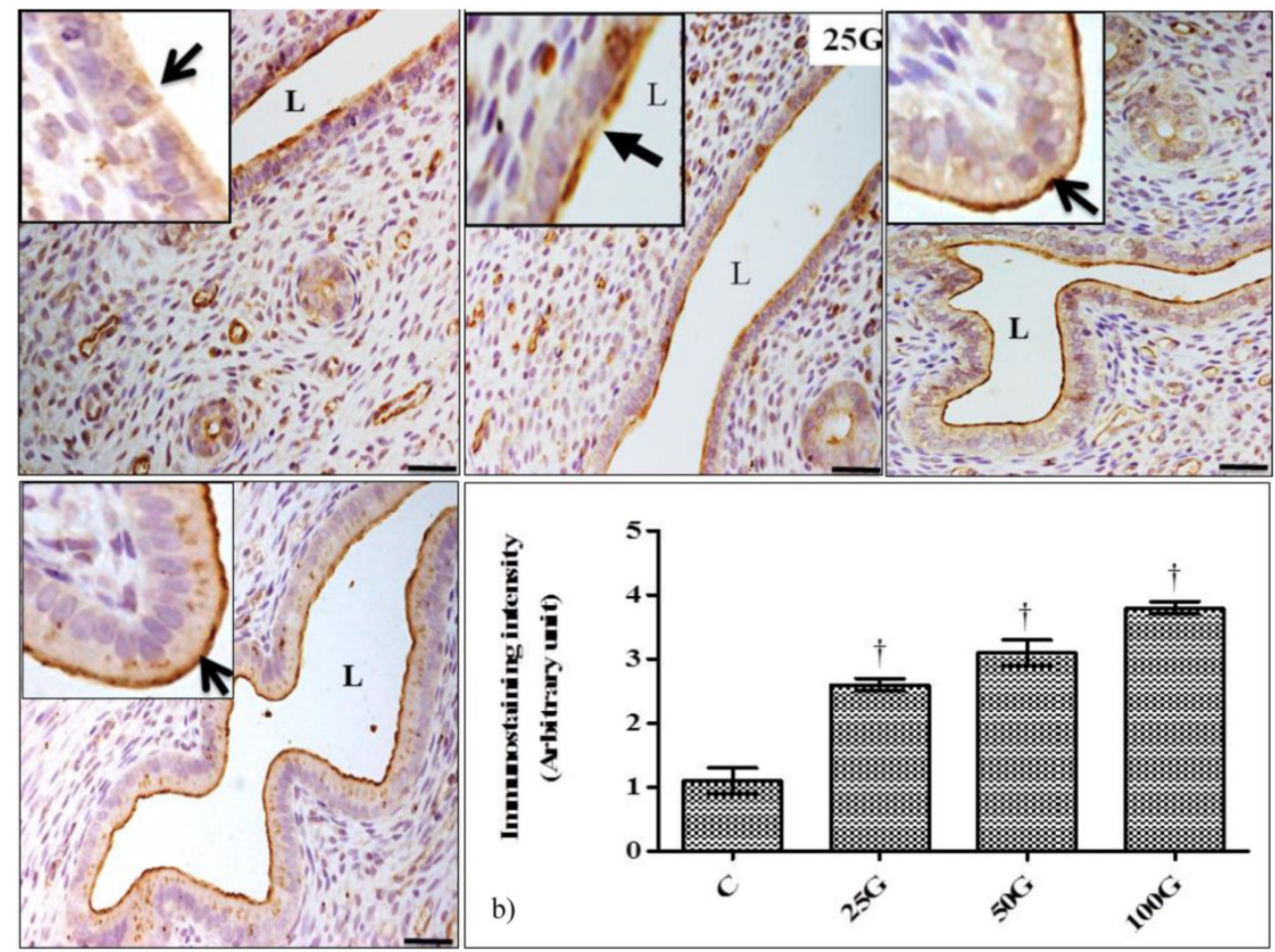

Figure 2: (a) Immunoperoxidase images of NHE- 1 distribution in cervix. High intensity dark-brown staining could be seen at the apical membrane of endocervical epithelia in 50 and $100 \mathrm{mg} / \mathrm{kg} /$ day genistein treatment groups. Mild staining was seen in $25 \mathrm{mg} / \mathrm{kg} /$ day genistein treatment group. (b) Quantitative analyses of peroxidase staining for NHE-1 in endocervical epithelia. The intensity of peroxidase staining was the highest in $100 \mathrm{mg} / \mathrm{kg} /$ day genistein treatment group. Staining intensity in all groups was higher than control. C: control, $25 \mathrm{G}$ : $25 \mathrm{mg} / \mathrm{kg} /$ day genistein, 50G: $50 \mathrm{mg} / \mathrm{kg} /$ day genistein, $100 \mathrm{G}: 100 \mathrm{mg} / \mathrm{kg} /$ day genistein. Arrows pointing toward NHE-1. † p $<0.05$ as compared to C. scale bar: $50 \mu \mathrm{m}$

a)
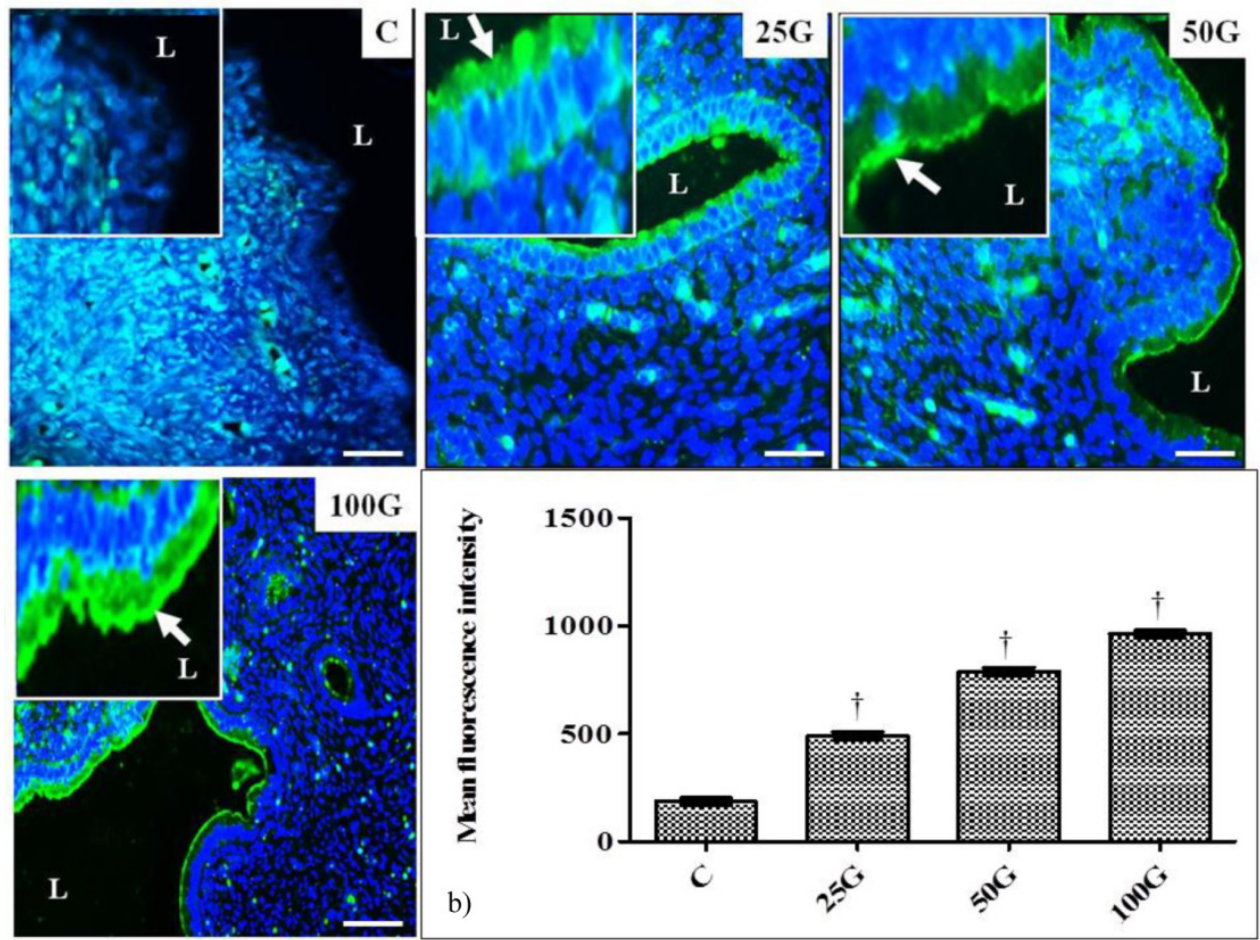

Figure 3: (a) Immunofluorescence images of NHE-2 distribution in cervix. High intensity fluorescence signals were observed at the apical membrane of endocervical epithelia in 100 $\mathrm{mg} / \mathrm{kg} /$ day genistein treatment group. Moderate signal was seen in 25 and $50 \mathrm{mg} / \mathrm{kg} /$ day genistein treatment groups. (b) Quantitative analyses of fluorescence signals for NHE-2 in endocervical epithelia under genistein influence. Fluorescence signal intensity was the highest in $100 \mathrm{mg} / \mathrm{kg} /$ day genistein treatment group. Signal intensity in all groups of treatments was higher than control. C: control, 25G: 25 mg/kg/day genistein, $50 \mathrm{G}: 50 \mathrm{mg} / \mathrm{kg} /$ day genistein, $100 \mathrm{G}: 100 \mathrm{mg} / \mathrm{kg} /$ day genistein. Arrows pointing toward NHE-2. † $<<0.05$ as compared to C. scale bar: $50 \mu \mathrm{m}$ 
a)
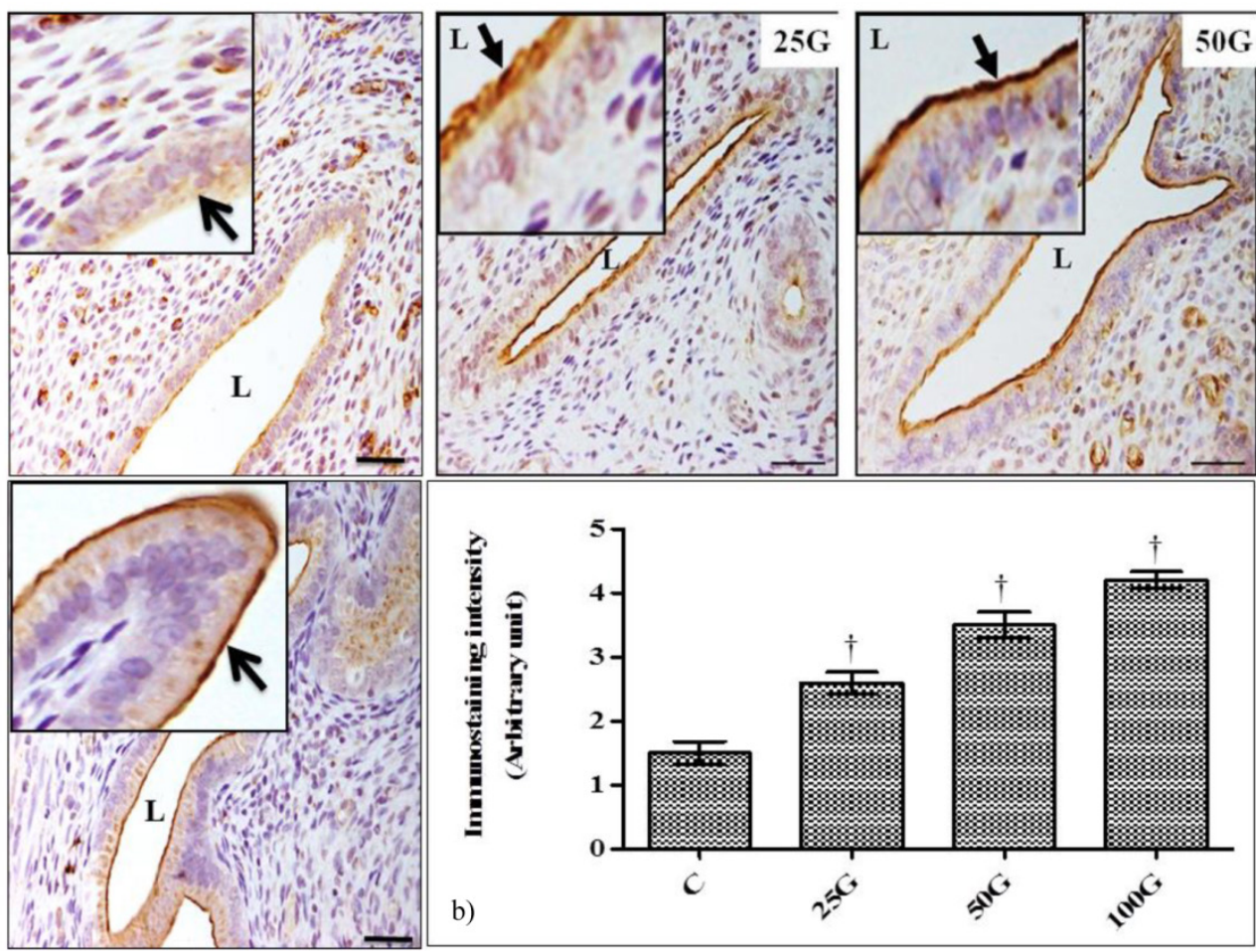

Figure 4: (a) Immunoperoxidase images of NHE-2 distribution in cervix. High intensity staining were observed at the apical membrane of endocervical epithelia in 100 and 50 $\mathrm{mg} / \mathrm{kg} /$ day genistein treatment groups. (b) Quantitative analyses of peroxidase staining for NHE-2 in endocervical epithelia. The intensity of peroxidase staining was the highest in $100 \mathrm{mg} / \mathrm{kg} /$ day genistein treatment group. Staining intensity in all groups was higher than control. C: control, $25 \mathrm{G}: 25 \mathrm{mg} / \mathrm{kg} / \mathrm{day}$ genistein, $50 \mathrm{G}: 50 \mathrm{mg} / \mathrm{kg} / \mathrm{day}$ genistein, $100 \mathrm{G}: 100 \mathrm{mg} / \mathrm{kg} / \mathrm{day}$ genistein. Arrows pointing toward NHE-2 isoform. $\dagger p<0.05$ as compared to C. scale bar: $50 \mu \mathrm{m}$

a)
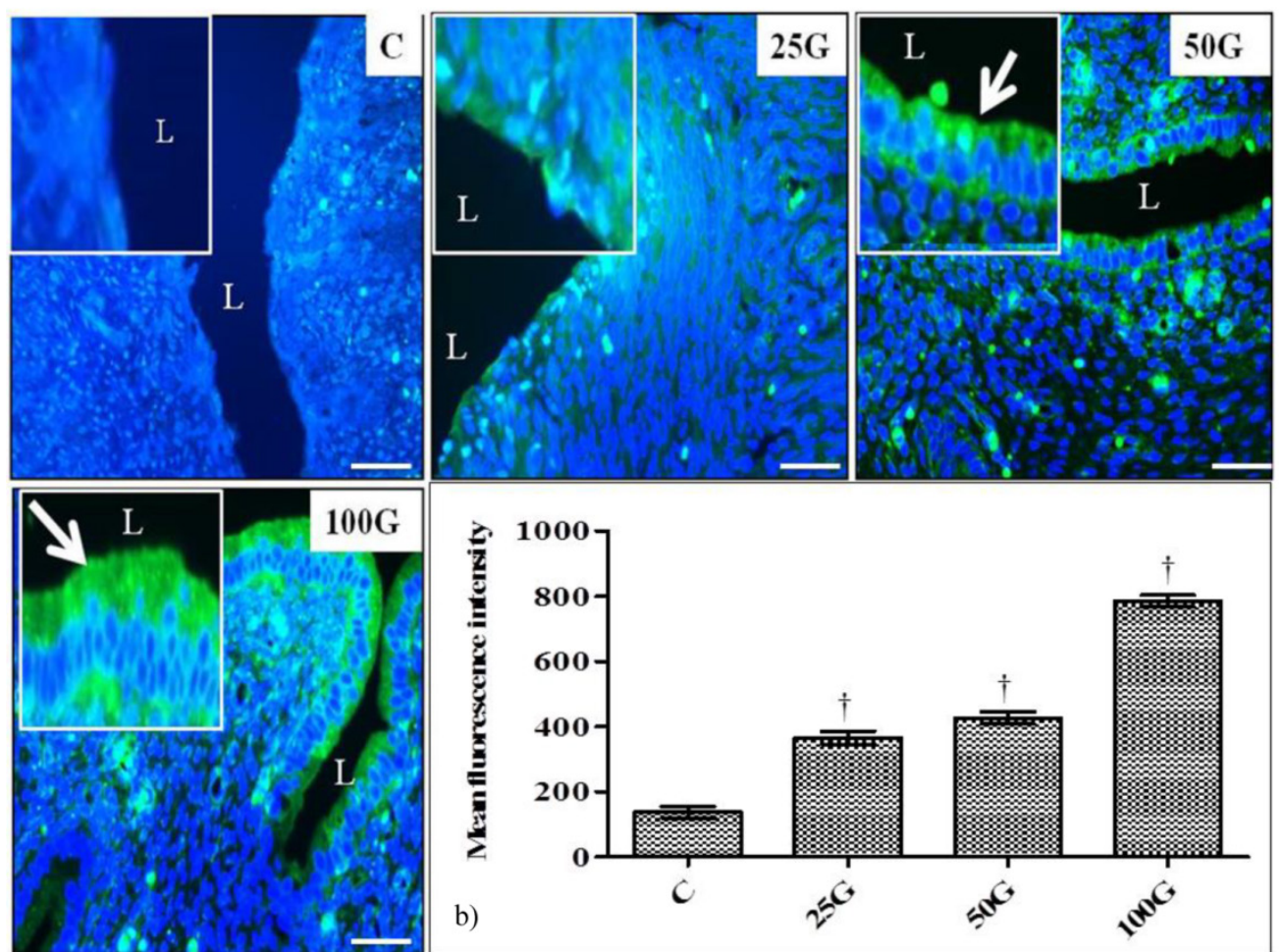

Figure 5: (a) Immunofluorescence images of NHE-4 distribution in cervix. High intensity signals could be seen at the apical membrane of endocervical epithelia in 50 and 100 $\mathrm{mg} / \mathrm{kg} /$ day genistein treatment groups. (b) Quantitative analyses of fluorescence signals for NHE-4 in endocervical epithelia under genistein influence. Fluorescence signal intensity was the highest in $100 \mathrm{mg} / \mathrm{kg} /$ day genistein treatment group. Signal intensity in all groups of treatment was higher than control. C: control, $25 \mathrm{G}$ : $25 \mathrm{mg} / \mathrm{kg} / \mathrm{day}$ genistein, $50 \mathrm{G}$ : 50 $\mathrm{mg} / \mathrm{kg} /$ day genistein, $100 \mathrm{G}: 100 \mathrm{mg} / \mathrm{kg} /$ day genistein. Arrows pointing toward NHE-4 isoform. $\dagger \mathrm{p}<0.05$ as compared to C. scale bar: $50 \mu \mathrm{m}$ 
a)

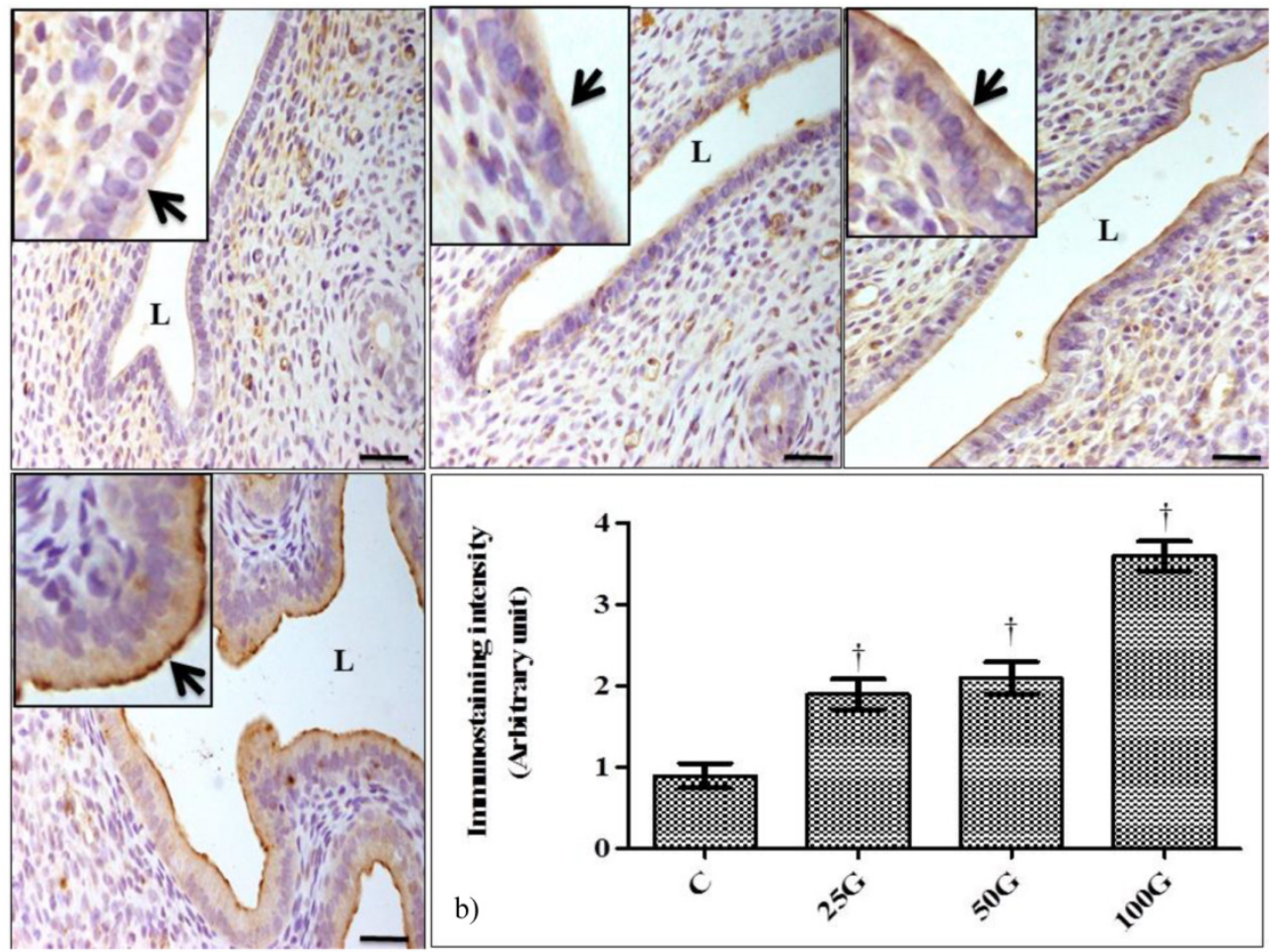

Figure 6: (a) Immunoperoxidase images of NHE-4 distribution in cervix. High intensity staining were observed at the apical membrane of endocervical epithelia in 100 and 50 $\mathrm{mg} / \mathrm{kg} / \mathrm{day}$ genistein treatment groups. (b) Quantitative analyses of peroxidase staining for NHE-4 in endocervical epithelia. The intensity of peroxidase staining was the highest in $100 \mathrm{mg} / \mathrm{kg} /$ day genistein treatment group. Staining intensity in all groups was higher than control C: control, $25 \mathrm{G}: 25 \mathrm{mg} / \mathrm{kg} / \mathrm{day}$ genistein, $50 \mathrm{G}: 50 \mathrm{mg} / \mathrm{kg} / \mathrm{day}$ genistein, $100 \mathrm{G}: 100 \mathrm{mg} / \mathrm{kg} / \mathrm{day}$ genistein. Arrows pointing toward NHE-4. $\dagger p<0.05$ as compared to C. scale bar: $50 \mu \mathrm{m}$

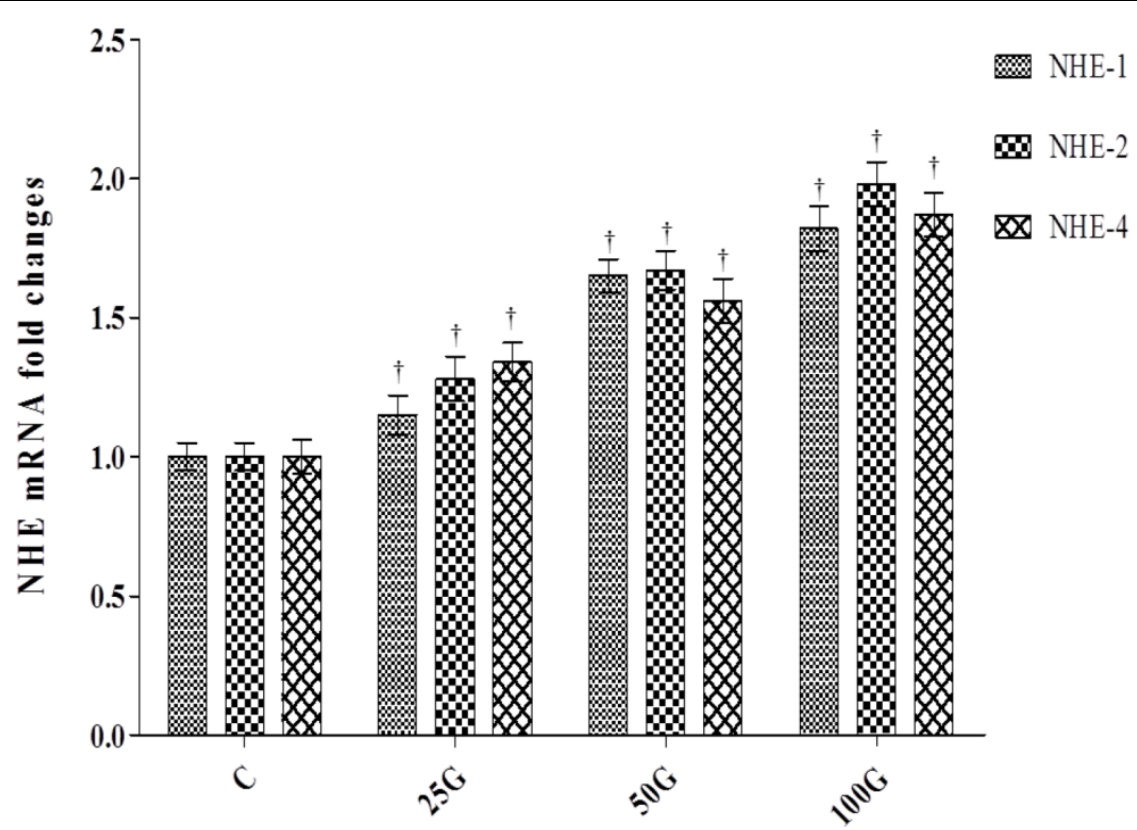

Figure 7: Expression of NHE-I, 2 and 4 mRNA in the cervix of genistein-treated ovariectomised rats. The highest mRNA levels for NHE-1, 2 and 4 were noted in $100 \mathrm{mg} / \mathrm{kg} / \mathrm{day}$ genistein treatment group. C: control, 25G: $25 \mathrm{mg} / \mathrm{kg} /$ day genistein, $50 \mathrm{G}: 50 \mathrm{mg} / \mathrm{kg} /$ day genistein, $100 \mathrm{G}: 100 \mathrm{mg} / \mathrm{kg} /$ day genistein $\dagger \mathrm{p}<0.05$ as compared to $\mathrm{C}$.

\section{Effect of ICI 182780 on NHE-I, 2 and 4 mRNA expression}

Figure 9 shows levels of expression of $N H E-1,2$ and 4 mRNAs in the cervical tissue homogenates of rats receiving $100 \mathrm{mg} / \mathrm{kg} /$ day genistein with or without ICI 182 780. Our findings indicated that administration of ICI 182780 in $100 \mathrm{mg} / \mathrm{kg} /$ day genistein treated rats significantly reduced the levels of expression all three NHE isoforms mRNAs as compared to $100 \mathrm{mg} / \mathrm{kg} /$ day genistein-only treatment. 
a)
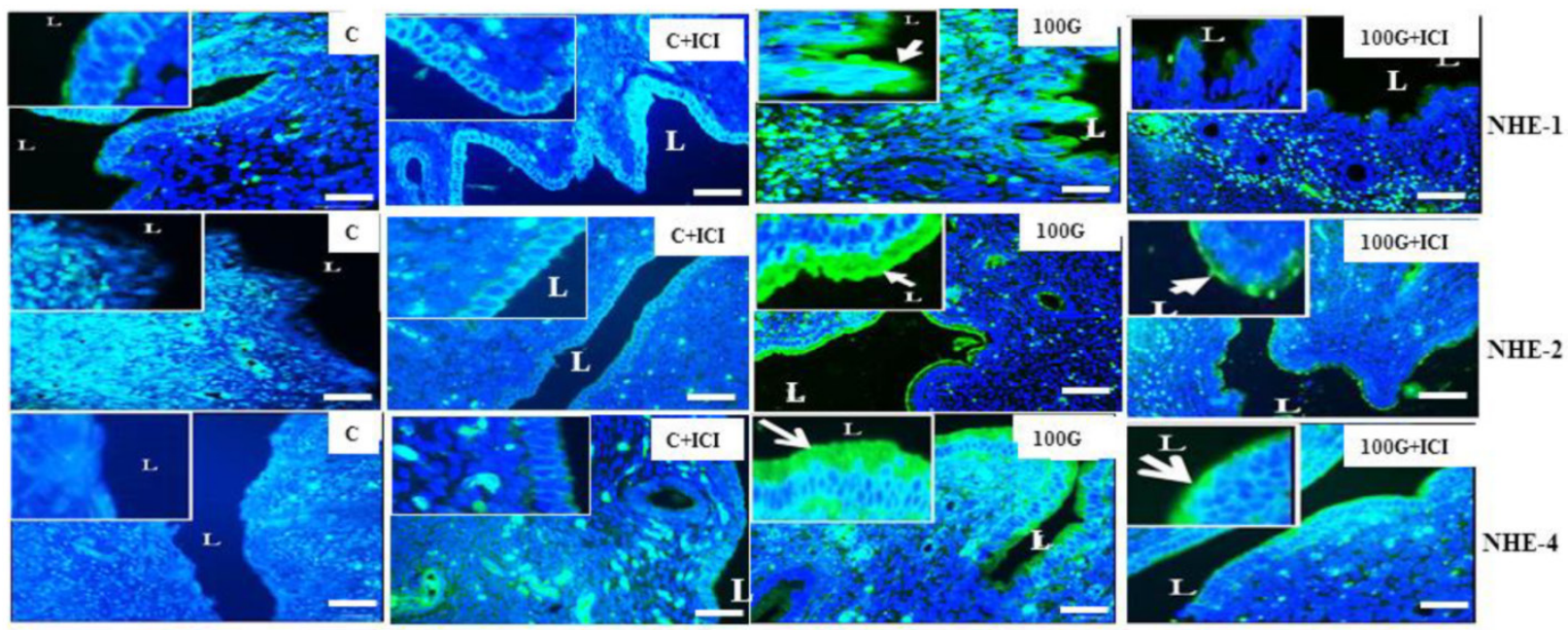

b)

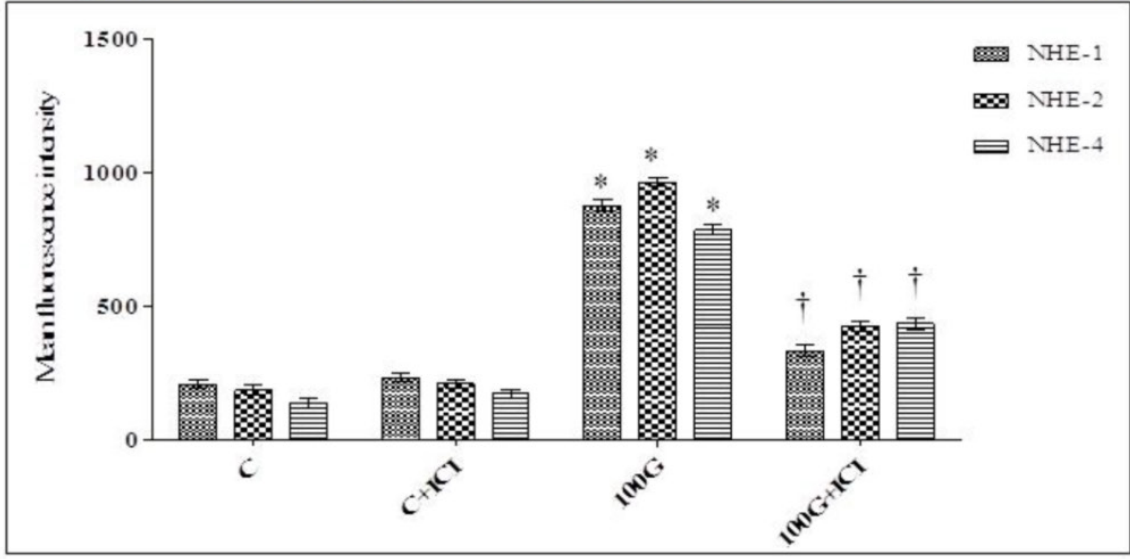

Figure 8: (a) Effect of ICI 182780 on distribution of NHE-1, 2 and 4 protein in cervix (b) Intensity of fluorescence signal in endocervical epithelium. Distribution and expression levels of NHE-1, 2 and 4 proteins in endocervical epithelia were markedly reduced in the group which received concomitant $100 \mathrm{mg} / \mathrm{kg} /$ day genistein and ICl 182780 treatment. No significant difference was noted between ICl 182780 only treatment and control. 100G: $100 \mathrm{mg} / \mathrm{kg} /$ day genistein. Arrows pointing toward NHE. * $p<0.05$ as compared to C. † p $<0.05$ as compared to $100 \mathrm{G}+\mathrm{ICl} 182780$.

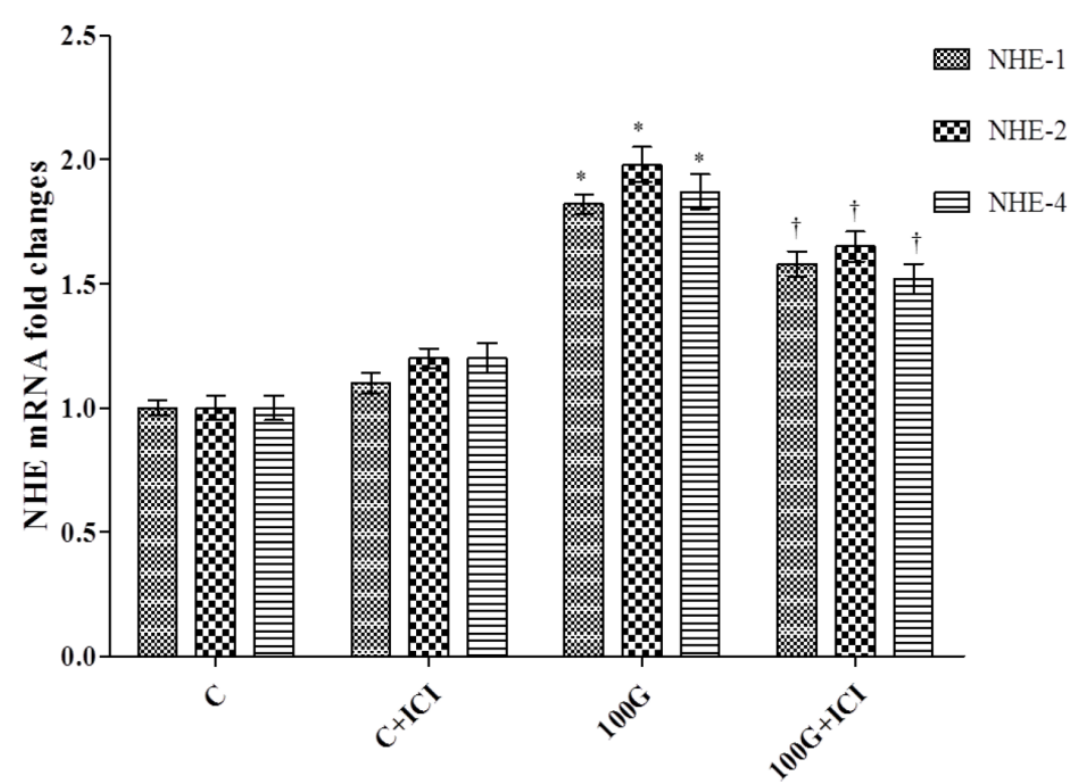

Figure 9: Effect of ICI 182780 on NHE-I, 2 and 4 mRNA levels in cervical tissue homogenates. Expression of NHE-I, 2 and 4 mRNA was significantly reduced in rats receiving concomitant $100 \mathrm{mg} / \mathrm{kg} /$ day genistein and ICl 182780 treatment as compared to $100 \mathrm{mg} / \mathrm{kg} /$ day genistein-only treatment. No significant difference was noted between ICl 182780 -only treatment and control. 100G: $100 \mathrm{mg} / \mathrm{kg} /$ day genistein. * $\mathrm{p}<0.05$ as compared to $\mathrm{C}$. $+\mathrm{p}<0.05$ as compared to $100 \mathrm{G}+\mathrm{ICl} 182780$. 


\section{Discussion}

This study has confirmed genistein upregulation of NHE isoforms expression in the cervix of rats that might contribute towards the beneficial effect of this compound in preventing cervicovaginal complications after menopause as a result of altered cervicovaginal fluid $\mathrm{pH}$. We have shown that administration of genistein at 50 and $100 \mathrm{mg} / \mathrm{kg} /$ day could enhance the expression of NHE-1, 2 and 4 in the cervix of sex-steroid deficient rats involving the estrogen receptor mediated pathway. Restoring the $\mathrm{pH}$ of cervical fluid could prevent pathologies in the cervix and vagina as alteration in cervical fluid $\mathrm{pH}$ might predispose cervix to pre-malignant changes, therefore increasing the risk of carcinoma [15]. Additionally, restoring the $\mathrm{pH}$ of the cervical fluid could help to restore the $\mathrm{pH}$ of vaginal fluid, that is essential for maintaining equilibrium of the vaginal flora [16]. This could prevent vaginal infection which is one of the most frequent complication of menopause [17].

Cervix is a sex-steroid responsive organ that responses to estrogen treatment. Estrogen stimulates increased in cervical fluid secretion [18], Both estrogen and progesterone affect the consistency of cervical mucus [8]. Estrogen has been shown able to influence the membrane transport processes in human cervical cell line in culture [19] and induces increase in cervical $\mathrm{HCO}_{3}{ }^{-}$secretion which contributed towards the alkaline cervical fluid $\mathrm{pH}$ [8]. Genistein, which is structurally related to estrogen and is widely consumed as a health supplement by the post-menopausal women was reported able to increase the $\mathrm{pH}$ of uterine fluid in post-menopausal rat model [13]. In view of this, there is a possibility that genistein could affect the cervical fluid $\mathrm{pH}$. In this study, there were evidences that genistein could affect the $\mathrm{pH}$ of cervical fluid in view that it was able to upregulate the expression of NHE isoforms 1, 2 and 4 in the epithelia lining the endocervical lumen. Increased in apical membrane expression of NHE could either help to increase the excretion of $\mathrm{H}^{+}$or to continuously maintain the excretion of $\mathrm{HCO}_{3}{ }^{-}$into the cervical lumen. This however warrants further investigations.

The involvement of NHE in the regeneration of $\mathrm{HCO}_{3}{ }^{-}$has been shown in the kidney [20] where high levels of NHE expression has been reported at the apical membrane which mediate $\mathrm{H}^{+}$efflux that could neutralize the $\mathrm{HCO}_{3}{ }^{-}$in the tubular fluid [20]. As proposed in the kidneys and uterus, $\mathrm{H}^{+}$will combine with $\mathrm{HCO}_{3}{ }^{-}$to form $\mathrm{H}_{2} \mathrm{CO}_{3}$ through the action of transmembrane carbonic anhydrase [21]. $\mathrm{H}_{2} \mathrm{CO}_{3}$ will then dissociates into $\mathrm{CO}_{2}$ and $\mathrm{H}_{2} \mathrm{O}$ which diffuse into the cells to form $\mathrm{H}_{2} \mathrm{CO}_{3}$ through the action of intracellular carbonic anhydrase [21]. Within the cells, $\mathrm{H}_{2} \mathrm{CO}_{3}$ will dissociate into $\mathrm{H}^{+}$and $\mathrm{HCO}_{3}^{-}$. In the kid- neys, $\mathrm{HCO}_{3}{ }^{-}$is reabsorbed into the plasma via basolateral membrane $\mathrm{HCO}_{3}{ }^{-}$transporters [22], while, in uterus, high expression of $\mathrm{HCO}_{3}$ transporters or examples CFTR [7] and SLC26A6 [13] at the apical membrane of the endometrial luminal epithelia assist in $\mathrm{HCO}_{3}{ }^{-}$extrusion into the lumen. [22] There is a possibility that $\mathrm{H}^{+}$excreted in the uterus through NHE might assist in $\mathrm{HCO}_{3}{ }^{-}$recycling that ensure continuous supply of $\mathrm{HCO}_{3}{ }^{-}$uterine lumen [13]. We speculated that similar mechanisms could occur in the cervix in which upregulation of NHE 1, 2 and 4 expression at the apical membrane of endocervical epithelia might help to ensure the continuous supply of $\mathrm{HCO}_{3}{ }^{-}$into the cervical lumen. Alternatively, increased expression of NHE-1, 2 and 4 might also help to enhance $\mathrm{H}^{+}$extrusion into the cervical lumen which contributed towards the reduction in cervical fluid $\mathrm{pH}$. Further studies are needed to confirm changes in the cervical fluid $\mathrm{pH}$ under genistein influence that could support either one of these possibilities. In the case that $\mathrm{NHE}$ enhances $\mathrm{H}^{+}$extrusion into the cervical lumen, reduction in cervical fluid $\mathrm{pH}$ could influence the $\mathrm{pH}$ of the vaginal fluid. High $\mathrm{H}^{+}$content could result in low vaginal fluid $\mathrm{pH}$ which could reduce the risk of vaginal infection after menopause [23]. The involvement of cervical NHE in vaginal fluid acidification could compliment the direct role of V-ATPase in mediating acidification of the vaginal fluid under estrogen or compounds with estrogenic effect [24]. The two possible consequences of genistein effect on the cervix are summarized in figure 10.

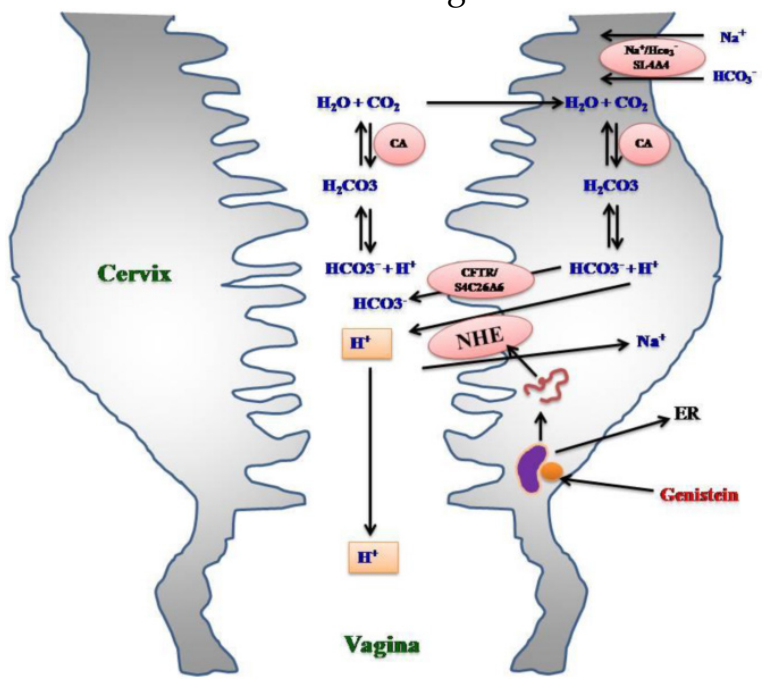

Figure 10: Hypothetical diagram showing the involvement of NHE isoforms in mediating possible effect of genistein on cervical and vaginal fluid $\mathrm{pH}$. Genistein binds to ER prior to inducing transcription of NHE-I, 2 and 4 genes in the cervix. This leads to increased expression of NHE-1, 2 and 4 proteins at the apical membrane of endocervical epithelia. NHE mediates $\mathrm{H}^{+}$extrusion into the cervical lumen. The extruded $\mathrm{H}^{+}$could either decrease the cervical $\mathrm{pH}$ which lead to a parallel decrease in vaginal $\mathrm{pH}$. Alternatively, extruded $\mathrm{H}^{+}$can combine with $\mathrm{HCO}_{3}$, which levels presumably increase under genistein influence through CFTR and SLC26A6 channels at the apical membrane. $\mathrm{H}^{+}$will combine with $\mathrm{HCO}_{3}$ - to form $\mathrm{H}_{2} \mathrm{CO}_{3}$ which through the action of transmembrane $\mathrm{CA}$, will generates $\mathrm{CO}_{2}$ and $\mathrm{H}_{2} \mathrm{O} . \mathrm{CO}_{2}$ and $\mathrm{H}_{2} \mathrm{O}$ traverse the apical membrane and will be reconverted to $\mathrm{H}^{+}$ and $\mathrm{HCO}_{3}{ }^{-}$via the action of intracellular CA.. ER: estrogen receptor, NHE: sodium proton exchanger, CFTR: cystic fibrosis transmembrane regulator, SLC26A^: chloride bicarbonate exchanger, SLC4A4: sodium bicarbonate cotransporter, CA: carbonic anhydrase. 
We concluded that enhanced expression of NHE 1, 2 and 4 isoforms in the endocervival epithelia could help to restore the cervicovaginal fluid $\mathrm{pH}$ after menopause. This might help to reduce the cervicovaginal complications related to menopause [25].

\section{Acknowledgement}

This study was funded by UMRG Grant (RG314-14AFR) University of Malaya, Kuala Lumpur, Malaysia.

\section{Conflict of interest}

The authors reported no conflict of interest in this study.

\section{References}

1. Cassidy A, Albertazzi P, Nielsen IL, Hall W, Williamson G, Tetens I, Atkins S, Cross H, Manios Y, Wolk A. Critical review of health effects of soyabean phyto-oestrogens in post-menopausal women. Proceedings of the Nutrition Society 2006; 65(01): 76-92

2. Squadrito F, Altavilla D, Morabito N, Crisafulli A, D'Anna R, Corrado F, Ruggeri P, Campo GM, Calapai G, Caputi AP. The effect of the phytoestrogen genistein on plasma nitric oxide concentrations, endothelin-1 levels and endothelium dependent vasodilation in postmenopausal women. Atherosclerosis $2002 ; 163(2)$ : 339-347

3. Morabito N, Crisafulli A, Vergara C, Gaudio A, Lasco A, Frisina N, D'Anna R, Corrado F, Pizzoleo MA, Cincotta M. Effects of Genistein and Hormone-Replacement Therapy on Bone Loss in Early Postmenopausal Women: A Randomized Double-Blind Placebo-Controlled Study. Journal of Bone and Mineral Research 2002; 17(10): 1904-1912

4. Crisafulli A, Marini H, Bitto A, Altavilla D, Squadrito G, Romeo A, Adamo EB, Marini R, D'Anna R, Corrado F. Effects of genistein on hot flushes in early postmenopausal women: a randomized, double-blind EPT-and placebo-controlled study. Menopause 2004; 11(4): 400-404

5. Newbold RR, Banks EP, Bullock B, Jefferson WN. Uterine adenocarcinoma in mice treated neonatally with genistein. Cancer Research 2001; 61(11): $4325-4328$

6. Jefferson WN, Padilla-Banks E, Newbold RR. Disruption of the female reproductive system by the phytoestrogen genistein. Reproductive Toxicology 2007; 23(3): 308-316

7. Chinigarzadeh A, Kassim NM, Muniandy S, Salleh N. Genistein-induced fluid accumulation in ovariectomised rats' uteri is associated with increased cystic fibrosis transmembrane regulator expression. Clinics 2014; 69(2): 111-119

8. Johnson MH. Essential reproduction. John Wiley \& Sons. 2012

9. Muchekehu RW, Quinton PM. A new role for bicarbonate secretion in cervico-uterine mucus release. The Journal of physiology 2010 - 588(13): 2329-2342

10. Chan HC, Ruan YC, He Q, Chen MH, Chen H, Xu WM, Chen WY, Xie C, Zhang $\mathrm{XH}$, Zhou $\mathrm{Z}$. The cystic fibrosis transmembrane conductance regulator in reproductive health and disease. The Journal of physiology 2009; 587(10): 2187-2195

11. Good DW. Sodium-dependent bicarbonate absorption by cortical thick ascending limb of rat kidney. American Journal of Physiology-Renal Physiology 248.1985; 6(): F821-F829

12. Gholami K, Muniandy S, Salleh N. Differential expression of $\mathrm{Na}+/ \mathrm{H}+$-exchanger (NHE-1, 2, and 4) proteins and mRNA in rodent's uterus under sex steroid effect and at different phases of the oestrous cycle. BioMed research international 2013 (2013)

13. Chinigarzadeh A, Kasim NF, Muniandy S, Kassim NM, Salleh N. Genistein Induces Increase in Fluid $\mathrm{pH}, \mathrm{Na}+$ and $\mathrm{HCO} 3-$ Concentration, SLC26A6 and SLC4A4 (NBCe1)-B Expression in the Uteri of Ovariectomized Rats. International journal of molecular sciences 2014; 15(1): 958-976

14. Lin $\mathrm{P}$, Lan X, Chen F, Yang Y, Jin Y, Wang A. Reference gene selection for real-time quantitative PCR analysis of the mouse uterus in the pe-ri-implantation period. PloS one 2013; 8(4): e62462

15. No JH, Jo H, et al. Expression of Vascular Endothelial Growth Factor and Hypoxia Inducible Factor-1a in Cervical Neoplasia. Annals of the New York Academy of Sciences 2009;1171(1): 105-110

16. Murta EF, Perfeito PB, Oliveira TM, Michelin MA, Maluf PJ. Relation between vaginal and endocervical $\mathrm{pH}$ in patients undergoing cold-knife conization and hysterectomy. Arch Gynecol Obstet 2008; 277(1): 43-46

17. Sánchez-Borrego R, et al. Position of the Spanish Menopause Society regarding vaginal health care in postmenopausal women. Maturitas 2014; 78(2): 146-150

18. Gorodeski GI. The Cultured Human Cervical Epithelium: A New Model for Studying Paracellular Transport. Journal of the Society for Gynecologic Investigation 1996; 3(5): 267-280
19. Gorodeski GI. Estrogen increases the permeability of the cultured human cervical epithelium by modulating cell deformability. American Journal of Physiology-Cell Physiology 1998; 275(3): C888-C899

20. Ford P, Rivarola V, Kierbel A, Chara O. Blot-Chabaud M, Farman N, Parisi M, Capurro C, Differential role of $\mathrm{Na}+\mathrm{H}+$ exchange isoforms NHE-1 and NHE-2 in a rat cortical collecting duct cell line. The Journal of membrane biology 2002; 190(2): 117-125

21. Gholami K, Muniandy S, Salleh N. In-Vivo Functional Study on the In-volvement of CFTR, SLC26A6, NHE-1 and CA Isoenzymes II and XII in Uterine Fluid $\mathrm{pH}$, Volume and Electrolyte Regulation in Rats under Different Sex-Steroid Influence. International journal of medical sciences 2013; 10(9): 1121

22. Hou J, Rajagopal M, Alan S. Claudins and the Kidney Volume 75: Annual Review of Physiology. Annual review of physiology 2013; 75(): 479

23. Boskey E, Telsch K, Whaley K, Moench T, Cone R. Acid production by vaginal flora in vitro is consistent with the rate and extent of vaginal acidifi-cation. Infection and immunity 1999; 67(10): 5170-5175

24. Gorodeski GI, Hopfer U, Liu CC, Margles E. Estrogen Acidifies Vaginal pH by Up-Regulation of Proton Secretion via the Apical Membrane of Vagi-nal-Ectocervical Epithelial Cells. Endocrinology 2005; 146(2): 816-824

25. Bulten J, de Wilde P, Schijf C, van der Laak JA, Wienk S, Poddighe PJ, Hanselaar AG. Decreased expression of Ki-67 in atrophic cervical epithelium of post-menopausal women. The Journal of pathology 2000; 190(5): 545-553 